\title{
ОБОСНОВАНИЕ БЕЗЭКСТРАКЦИОННЫХ МЕТОДОВ ОРТОДОНТИЧЕСКОГО ЛЕЧЕНИЯ ПАЦИЕНТОВ
}

\section{JUSTIFICATION OF NON-EXTRACTIVE METHODS OF ORTHODONTIC TREATMENT OF PATIENTS}

\author{
A. Sevastyanov \\ M. Rozhkova \\ S. Fishchev \\ A. Lepilin \\ I. Orlova \\ M. Puzdyreva \\ N. Vasilyeva \\ A. Shtorina
}

Summary. Relevance. An alternative to tooth extraction is to normalize the shape of the dental arches, by increasing their size in the sagittal and transversal directions. In the treatment of skeletal forms of anomalies, an alternative to tooth extraction is to modify the growth of the jaws by orthodontic methods or change the size and position of the jaws by surgical methods. In some cases, a combination of these methods of treatment is recommended. The purpose of the study. Optimization of non-extraction methods of treatment of patients, the first period of adulthood, with anomalies of the shape and size of the dental arches in accordance with the morphometric and functional parameters of the craniofacial complex.

Materials and methods. When performing this work, 1,493 people, the first period of adulthood, residents of St. Petersburg were examined. The comparison group consisted of 1115 people, it included 828 patients with physiological occlusion of permanent teeth and various variants of the shape and size of the dental arches (dolicho -, brachiand mesognathic with their normal, macro-and microdontism). Various forms of optimal functional occlusion were determined in 287 people. The main methods of the clinical trial were carried out according to generally accepted methods in accordance with the protocol. Morphometric data, functional and aesthetic disorders were evaluated. An objective examination of the organs of the maxillofacial region was carried out, taking into account the recommendations of specialists. Results and discussion. Variability in the size of permanent teeth was found in all varieties of dental arches. For each of the 9 forms of dental arches, the main biometric parameters were characteristic, which can be used to determine the size of metal arches used at various stages of orthodontic treatment. Conclusions. Based on the morphometric parameters of the maxillofacial region, a classification of dental arches in physiological occlusion of permanent teeth is proposed. There are 9 main forms of dental arches: mesognatic normodont, mesognatic microdont, mesognatic macrodont, dolichognatic normodont, dolichognatic microdont, dolichognatic macrodont, brachignatic normodont, brachignatic microdont, brachignatic macrodont.
Севастьянов Аркадий Владимирович

Д.м.н., дочент, Санкт-Петербургский государственный педиатрический медицинский университет Министерства здравоохранения РФ ardy.dkr@mail.ru

Рожкова Мария Геннадьевна

Ассистент, Санкт-Петербургский государственный педиатрический медицинский университет Министерства здравоохранения РФ

rozmaria2010@yandex.ru

Фищев Сергей Борисович

Д.м.н., профессор, Санкт-Петербургский государственный педиатрический медичинский университет Министерства здравоохранения РФ super.kant@yandex.ru

Лепилин Александр Викторович

Д.м.н., профессор, Саратовский государственный медицинский университет имени В.И. Разумовского Министерства здравоохранения РФ lepilins@mail.ru

Орлова Ирина Викторовна

К.м.н., доцент, Санкт-Петербургский государственный педиатрический медицинский университет Министерства здравоохранения РФ

orisha@mail.ru

Пуздырева Маргарита Николаевна

К.м.н., ассистент, Санкт-Петербургский государственный педиатрический медичинский университет Министерства здравоохранения РФ seven-spb@yandex.ru

Васильева Нелли Александровна Ассистент, Санкт-Петербургский государственный педиатрический медичинский университет Министерства здравоохранения РФ vas.nell@yandex.ru

Шторина Анастасия Александровна

К.м.н., ассистент, Санкт-Петербургский государственный педиатрический медицинский университет Министерства здравоохранения РФ nastiya78@mail.ru

Аннотация. Актуальность. Альтернативой удалению зубов является нормализация формы зубных дуг, за счет увеличения их размеров в сагиттальном и трансверсальном направлениях. При лечении скелетных форм аномалий альтернативой удалению зубов является модификация роста челюстей ортодонтическими методами или изменение размеров и положения челюстей хирургическими методами. В ряде случаев рекомендуют сочетание этих методов лечения. 


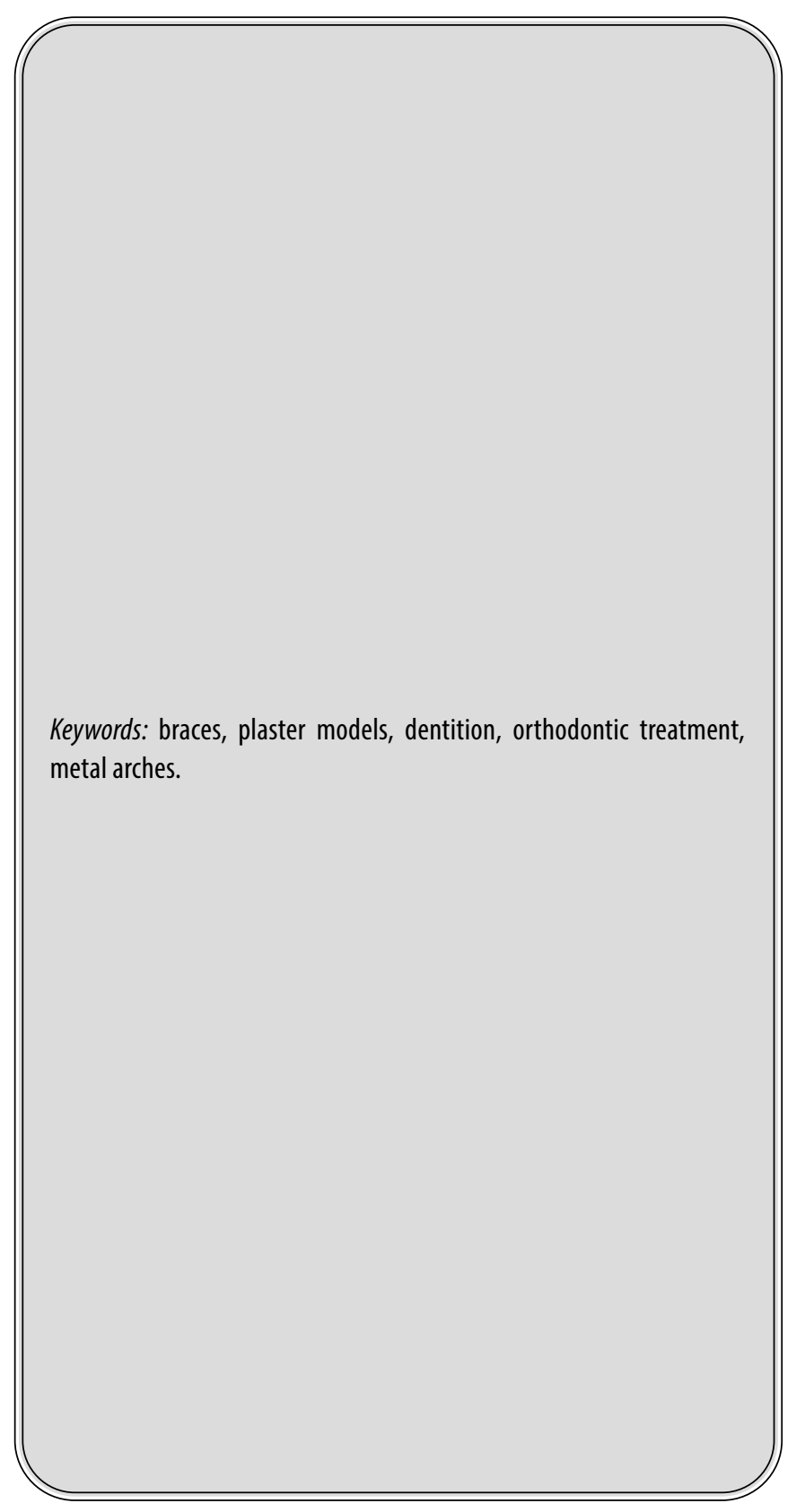

\section{Актуальность}

сновными причинами удаления отдельных зубов по ортодонтическим показаниям считают дефицит места при несоответствии размеров зубных дуг параметрам челюстей и камуфляж скелетных аномалий окклюзии в сагиттальном направлении $(1,2,3,4)$. Альтернативой удалению, в первом случае, является нормализация формы зубных дуг, за счет увеличения их размеров в сагиттальном и трансверсальном направлениях. При лечении скелетных форм аномалий альтернативой удалению зубов является модификация роста челюстей ортодонтическими методами или изменение размеров и положения челюстей хи-
Цель исследования. Оптимизация безэкстракционных методов лечения пациентов, первого периода зрелого возраста, с аномалиями формы и размеров зубных дуг в соответствии с морфометрическим и функциональным параметрами краниофациального комплекса.

Материалы и методы. При выполнении настоящей работы обследовано 1493 человека, первого периода зрелого возраста, жителей г. Санкт-Петербурга.

Группу сравнения составили 1115 человек в нее вошли 828 пациентов с физиологической окклюзией постоянных зубов и различными вариантами формы и размеров зубочелюстных дуг (долихо-, брахи- и мезогнатические при их нормо-, макро- и микродонтизме). У 287 человек определялись различные формы оптимальной функциональной окклюзии.

Основные методы клинического исследования проводились по общепринятым методикам в соответствии с протоколом. Оценивались морфометрические данные, функциональные и эстетические нарушения. Проводилось объективное обследование органов челюстно-лицевой области с учетом рекомендаций специалистов.

Результаты и обсуждение. Вариабельность размеров постоянных зубов встречалась при всех разновидностях зубочелюстных дуг. Для каждой из 9 форм зубочелюстных дуг были характерны основные биометрические параметры, которые могут быть использованы при определении размеров металлических дуг, используемых на различных этапах ортодонтического лечения.

Выводы. На основании морфометрических параметров челюстно-лицевой области предложена классификация зубочелюстных дуг при физиологической окклюзии постоянных зубов. Выделены 9 основных форм зубных дуг: мезогнатическая нормодонтная, мезогнатическая микродонтная, мезогнатическая макродонгная, долихогнатическая нормодонтная, долихогнатическая микродонтная, долихогнатическая макродонгная, брахигнатическая нормодонтная, брахигнатическая микродонтная, брахигнатическая макродонгная.

Ключевые слова: брекеты, гипсовые модели, зубные ряды, ортодонтическое лечение, металлические дуги.

рургическими методами. В ряде случаев рекомендуют сочетание этих методов лечения.

Рекомендации специалистов по экстракционным и безэкстракционным методам комплексного лечении аномалий и деформаций челюстно-лицевой области меняются от одной точки зрения, к противоположной, и до сих пор этот маятник не остановлен $(5,6,7,8,9)$.

\section{Цель исслеАования}

Оптимизация безэкстракционных методов лечения пациентов, первого периода зрелого возраста, с аномалиями формы и размеров зубных дуг в соответствии 
с морфометрическим и функциональным параметрами краниофациального комплекса.

\section{Материалы и методы исслеАОвания}

При выполнении настоящей работы нами обследовано 1493 человека, первого периода зрелого возраста, жителей г. Санкт-Петербурга.

Пациенты, которым проводилось лечение патологии окклюзионных взаимоотношений, были разделены на две основные группы. В первую группу входили 203 пациента, которым проводили лечение без удаления зубов. У пациентов второй группы (175 человек) применяли экстракционные методы лечения.

В каждой группе было выделено по две подгруппы. У пациентов первой подгруппы определялось соответствие одонтометрических показателей основным параметрам челюстно-лицевой области, у пациентов второй подгруппы размеры зубов не соответствовали параметрам кранио-фациального комплекса.

Группу сравнения составили 1115 человек в нее вошли 828 пациентов с физиологической окклюзией постоянных зубов и различными вариантами формы и размеров зубочелюстных дуг (долихо-, брахи- и мезогнатические при их нормо-, макро- и микродонтизме). у 287 человек определялись различные формы оптимальной функциональной окклюзии.

Основные методы клинического исследования проводились по общепринятым методикам в соответствии с протоколом. Оценивались морфометрические данные, функциональные и эстетические нарушения. Проводилось объективное обследование органов челюстно-лицевой области с учетом рекомендаций специалистов.

В клинике использовали специальные методы исследования: краниометрические методы, биометрическое исследование моделей челюстей, ортопантомографию, телерентгенографию, фотографический метод.

Для диагностики использовали классификацию аномалий окклюзии Л.С. Персина (1989).

В сагиттальном направлении измерялась длина головы (g-op). Диагональ лица измерялась как расстояние от козелка уха (точка «t») до субназальной точки «sn». Условную глубину гнатической части лица определяли математически, как высоту условного прямоугольного треугольника «t-sn-t».
Ширина лица сравнивалась с шириной зубной дуги между вторыми постоянными молярами. Ширина наружного носа сравнивалась с шириной зубной дуги в области клыков, а глубина гнатической части лица с глубиной зубной дуги.

Измерения зубов проводили на гипсовых моделях челюстей и в полости рта. При этом пользовались одонтометрическим электронным штангенциркулем с точностью измерения до 0,01 мм. Определяли размеры коронок зубов в вестибулярно-язычном и медиально-дистальном направлении. Проводили расчет интердентальных соотношений.

Процентное соотношение суммы медиально-дистальных диаметров 4 резцов верхней челюсти с шириной лица (zy-zy) определяло дентально-фациальный индекс. При нормодонтизме постоянных верхних резцов указанный индекс составлял $23,5 \% \pm 1,5 \%$. Величина индекса менее 21,9\% характеризовала индивидуальный микродонтизм, а более $25,1 \%$ - макродонтизм постоянных резцов.

Принадлежность зубов к макро-, микро- или нормодонтной системам определялась по среднему модулю моляров, который составлял полусумму модуля первого и второго моляра. При этом модуль моляра составлял половину от суммы вестибулярно-язычного и мезиально-дистального диаметров коронки. Величина среднего модуля при нормодонтизме составляла 10,8土0,2 мм. Для микродонтизма была характерна величина модуля менее 10,59 мм, а для макродонтизма - более 11,1 мм.

При определении соответствия размеров зубов верхней челюсти размерам нижних зубов

\section{Результаты исслеАования и их обсу>}

Результаты проведенного нами исследования пациентов группы сравнения показали, что при физиологической окклюзии встречались 9 основных вариантов формы зубных дуг. У лиц с мезогнатическими, брахигнатическими и долихогнатическими формами зубных дуг определялись варианты микродонтизма, нормодонтизма и макродонтизма постоянных зубов.

у большинства людей с физиологической окклюзией постоянных зубов был мезогнатический тип зубочелюстных дуг, который был выявлен у 363 человек, что составило $43,85 \pm 1,72 \%$ от числа пациентов группы сравнения. Причем у 232 человек $(28,02 \pm 1,56 \%)$ определялся нормодонтизм, у 66 человек - макродонтизм и у 65 пациентов - микродонтизм постоянных зубов. 
Долихогнатическая форма зубочелюстных дуг была у 208 человек $(25,12 \% \pm 1,51 \%)$, которая сочеталась с нормодонтизмом у 75 человек $(9,06 \% \pm 0,99 \%)$, с макродонтизмом - у 108 человек (13,04\% $\pm 1,17 \%)$, а с микродонтизмом - у 25 человек (3,02\% $\pm 0,59 \%)$.

При брахигнатической форме зубочелюстных дуг нормодонтизм был у 116 человек (14,01\% $\pm 1,2 \%)$, а микродонтизм - у 83 человек $(10,02 \% \pm 1,04 \%)$. Реже брахигнатическая форма встречалась у лиц с макродонтизмом (58 человек).

Таким образом, вариабельность размеров постоянных зубов встречалась при всех разновидностях зубочелюстных дуг. Тем не менее, для мезогнатических дуг был характерен нормодонтизм. При долихогнатической форме чаще определялся макродонтизм постоянных зубов. При брахигнатической форме - нормодонтизм.

Таким образом, для каждой из 9 форм зубочелюстных дуг были характерны основные биометрические параметры, которые могут быть использованы при определении размеров металлических дуг, используемых на различных этапах ортодонтического лечения.

У лиц, которым ранее проводилось ортодонтическое лечение, была оптимальная функциональная окклюзия, при которой определялось большинство из основных «ключей» окклюзии, однако было характерным несоответствие одонтометрических показателей кефалометрическим и гнатометрическим параметрам, а в некоторых случаях контакты первых постоянных моляров верхней и нижней челюсти не соответствовали нейтральному положению.

Нами выделены четыре основных варианта оптимальной функциональной окклюзии: оптимальная функциональная окклюзия при полном комплекте постоянных зубов и несоответствием одонтометрических показателей кефалометрическим и гнатометрическим параметрам 1 степени; оптимальная функциональная окклюзия при неполном комплекте постоянных зубов и неравном количестве антагонистов, но одинаковом количестве антимеров (соотношение первых постоянных моляров по II или III классу); оптимальная функциональная окклюзия при неполном комплекте постоянных зубов и равном количестве антагонистов (удалены 4 зуба, например премоляры); оптимальная функциональная окклюзия при наличии искусственных зубов, замещающих дефекты зубных рядов.

Выявленные особенности вариантов оптимальной функциональной окклюзии нами использовались в качестве эталона при планировании ортодонтического лечения пациентов с аномалиями и деформациями зубочелюстных дуг.

Учитывая многообразие аномалий и деформаций зубочелюстных дуг, характеризующихся сужением, укорочением, удлинением, краудингом, ретенцией и полуретенцией зубов, в сочетании с дефектами зубных рядов различной протяженности и локализации, осложненных и не осложненных деформациями в различных направлениях нами предложены диагностические схемы определения аномалий, алгоритмы обследования пациентов с аномалиями, обоснованы показания к удалению отдельных зубов. Дана балльно-рейтинговая система оценки состояния окклюзионных взаимоотношений при различных вариантах формы и размеров зубочелюстных дуг, включая и их аномалии.

Физиологическая окклюзия при различных вариантах формы и размеров зубов и зубочелюстных дуг оценивалась от 81 до 100 баллов. Состояние окклюзионных взаимоотношений при различных вариантах оптимальной функциональной окклюзии оценивалось нами в диапазоне 61-80 баллов.

Состояние окклюзионных взаимоотношений у пациентов с аномалиями и деформациями зубочелюстных дуг и мезогнатической зубной системой, при которй определялось соответствием одонтометрических показателей гнатометрическим и кефалометрическим параметрам оценивались в 51-60 баллов.

Состояние окклюзионных взаимоотношений при аномалиях и деформациях зубных дуг у пациентов с долихогнатическими или брахигнатическими зубными системами и соответствием одонтометрических показателей кефалометрическим и гнатометрическим параметрам оценивались в 41-50 баллов.

При несоответствии одонтометрических показателей кефалометрическим и гнатометрическим параметрам в зависимости от степени выраженности и количества зубов состояние окклюзионных взаимоотношений оценивалось от 11 до 40 баллов. Гнатические формы аномалий окклюзии были оценены от 0 до 10 баллов.

Таким образом, предложенные методы исследования и балльно-рейтинговая система оценки окклюзионных взаимоотношений, позволили определять тактику ортодонтического лечения и оценит эффективность проведенных методов комплексного лечения пациентов в исследуемых группах.

В результате проведенного исследования и с учетом анализа используемой литературы установлено, удаление постоянных зубов при ортодонтическом лечении 
рекомендовано проводить при несоответствии одонтометрческих показателей гнатометрическим и кефалометрическим параметрам второй и третьей степени. К тому же компенсаторное удаление зубов проводилось при отсутствии одного из антимеров в случае дефицита места для зубов в зубочелюстных дугах.

Альтернативой экстракционным методам было: выбор формы дуги и прописи брекетов у пациентов при соответствии одонтометрических показателей гнатометрическим и кефалометрическим параметрам.

При лечении аномалий и деформаций зубочелюстных дуг у пациентов с микродонтной зубной системой, как правило, применялись безэкстракционные методы лечения. Так же экстракционные методы лечения были нецелесообразны при лечении пациентов, у которых размеры зубов соответствовали кефалометрическим и гнатометрическим параметрам. В этих случаях при аномалиях и деформациях зубных дуг была рекомендована реконструкция зубных дуг в соответствии с параметрами краниофациального комплекса.

Для получения мезогнатической нормодонтной формы зубочелюстных дуг было рекомендовано использовать металлические дуги «среднего» размера. При макродонтизме более рациональными были дуги «большого» размера, а при микродонтизме - малого размера. Наиболее целесообразной прописью брекетов был «стандартный» торк.

При конструировании долихогнатических форм применялись брекеты с «высоким» торком, а форма дуг определялась размерами зубов. Малые дуги применялись у пациентов при нормо- и микродонтизме, а «средние» размеры - при макродонтизме постоянных зубов.

Брахигнатические формы получали с использованием брекетов с низким торком. Однако при нормои мкродонтизме использовались металлические дуги «большого» размера, а при микродонтизме - среднего размера.

При несоответствии одонтометрических показателей гнатометрическим и кефалометрическим параметрам I степени альтернативой экстракционным методам лечения служил выбор металлических дуг и выбор прописи брекетов для получения оптимальной функциональной окклюзии.

При этом у пациентов с мезогнатическими нормодонтными формами использовали брекеты с «высоким» торком, а металлические дуги - среднего размера. В связи с этим после лечения параметры зубных дуг были близки к долихогнатической макродонтной форме, а окклюзионные взаимоотношения соответствовали признакам оптимальной функциональной окклюзии.

У пациентов с мезогнатическими макродонтными зубными системами более рациональными были экстракционные методы лечения аномалий даже при дефиците места в зубной дуге I степени. После альтернативного безэкстракционного лечения в этих случаях сохранялось напряжение в зубных дугах, что, нередко, способствовало рецидиву патологии.

У пациентов с долихогнатическими нормодонтными формами зубных дуг альтернативой экстракционным методам лечения являлось применение брекетов с высоким торком и использованием металлических дуг среднего размера. Полученные в ходе лечения окклюзионные взаимоотношения соответствовали признакам оптимальной функциональной окклюзии, а размеры зубных дуг были близки к параметрам, полученным у лиц с долихогнатической макродонтной системой.

\section{Выво $\triangle \mathrm{b}$}

1. На основании морфометрических параметров челюстно-лицевой области предложена классификация зубочелюстных дуг при физиологической окклюзии постоянных зубов. Выделены 9 основных форм зубных дуг: мезогнатическая нормодонтная, мезогнатическая микродонтная, мезогнатическая макродонгная, долихогнатическая нормодонтная, долихогнатическая микродонтная, долихогнатическая макродонгная, брахигнатическая нормодонтная, брахигнатическая микродонтная, брахигнатическая макродонгная.

2. Разработана балльно-рейтинговая система оценки окклюзионных взаимоотношений, при которой физиологическая окклюзия оценивалась в диапазоне от 81 до 100 баллов в зависимости от вариантов формы и размеров зубов и зубочелюстных дуг. Оптимальная функциональная окклюзия была оценена в диапазоне от 61до 80 баллов. Зубоальвеолярные формы аномалий и деформаций челюстно-лицевой области оценивались в диапазоне от 11 до 60 баллов в зависимости от выраженности патологии и соответствии одонтометических показателей гнатометрическим параметрам. Гнатические форы аномалий оценивали в диапазоне от 1 до 10 баллов.

3. При лечении пациентов с аномалиями окклюзии и соответствии одонтометрических показателей гнатометрическим параметрам рекомендована реконструкция зубных дуг в соответствии с индивидуальными параметрами краниофациального комплекса. Для получения мезогнатической 
формы зубной дуги у пациентов с нормодонтизмом постоянных зубов рекомендовано использовать металлические дуги «среднего» размера. При макродонтизме более рациональными были дуги «большого» размера, а при микродонтизме - малого размера. Наиболее целесообразной прописью брекетов был «стандартный» торк. При конструировании долихогнатических форм необходимо применять брекеты с «высоким» торком. Малые дуги применялись у пациентов при нормо- и микродонтизме, а «средние» размеры - при макродонтизме постоянных зубов.
Брахигнатические формы получали с использованием брекетов с низким торком. Однако при нормо- и мкродонтизме использовались металлические дуги «большого» размера, а при микродонтизме - среднего размера. Соблюдение этих рекомендаций позволяло проводить безэкстракционные методы лечения.

4. Несоответствие размеров зубов параметрам зубочелюстных дуг второй и третьей степени определяло показания к экстракционным методам лечения пациентов с различными вариантами зубочелюстных дуг.

\section{ЛИТЕРАТУРА}

1. Давыдов Б.Н., Доменюк Д.А., Дмитриенко С.В., Коробкеев А.А., Арутюнова А.Г. Морфологические особенности строения лицевого скелете и клинико-диагностические подходы к лечению зубочелюстных аномалий у детей в периоде раннего сменного прикуса // Стоматология детского возраста и профилактика. - 2019. - Т. 19. — № 1 (69). - С. 26-38.

2. Данилова М.А., Газизуллина 0.Р. Сочетанный метод лечения пациентов с зубочелюстно-лицевыми аномалиями несъемной техникой и эластопозиционерами // Фундаментальные исследования. — 2013.— № 9 (часть 4).—C. 632-636.

3. Данилова М.А., Залазаева Е.А. Междисциплинарный подход к диагностике, профилактике и коррекции зубочелюстных и речевых нарушений у детей с церебральным параличом // Российская стоматология.— 2018. - Т. 11, № 3. - С. 45-48.

4. Климов А.Г., Рожкова М.Г., Лепилин А.В. и др. Электромиографические показатели у пациентов с дефицитом места в зубном ряду // Современная наука: актуальные проблемы теории и практики. Естественные и технические науки. — 2021. — № 1.— С. 152-156.5. Рожкова М.Г., Лепилин А.В., Кондратюк А.А. и др. Морфологические особенности различных физиологических вариантов окклюзионных взаимоотношений // Современная наука: актуальные проблемы теории и практики. Серия «Естественные и технические науки».— 2021.— № 1.— С. 152-156.

5. Bulyalert A. Pimkhaokham A. A novel classification of anterior alveolar arch forms and alveolar bone thickness: A cone-beam computed tomography study // Imaging. Sci. Dent. — 2018. — Vol. 48. — № 3.—P. 191-199.

6. Camardella L.T., Sá B., Guimarães L.C. Agreement in the determination of preformed wire shape templates on plaster models and customized digital arch form diagrams on digital models // Am.J. Orthod. Dentofacial. Orthop.— 2018.—Vol. 153.— № 3.—P. 377-386.

7. Tiwari A., Gard A., Virang B. Arch form in orthodontics: a review // J. App. Dent. Med. Sci. — 2018. Vol. 4. — № 1.— P. 118-127.

8. Dmitrienko S.V., Domenyuk D.A., Kochkonyan A.S., Karslieva A.G., Dmitrienko D.S. Modern classification of dental arches // Archiv EuroMedica.—2014.T. 4. 一 № 2.—C. 14-16.

9. Dmitrienko S.V., Fomin I.V., Domenyuk D.A., Kondratyuk A.A., Subbotin R.S. Enhancement of research method for spatial location of temporomandibular elements and maxillary and mandibular medial incisors //Archiv EuroMedica. — 2019. — T. 9. — № 1. — P. 38-44.

\footnotetext{
( С Севастьянов Аркадий Владимирович ( ardy.dkr@mail.ru ), Рожкова Мария Геннадьевна ( rozmaria2010@yandex.ru ),

Фищев Сергей Борисович ( super.kant@yandex.ru ), Лепилин Александр Викторович ( lepilins@mail.ru ),

Орлова Ирина Викторовна ( orisha@mail.ru ), Пуздырева Маргарита Николаевна ( seven-spb@yandex.ru ),

Васильева Нелли Александровна ( vas.nell@yandex.ru ), Шторина Анастасия Александровна ( nastiya78@mail.ru ).

Журнал «Современная наука: актуальные проблемы теории и практики»
} 